Se clasifica en tres grupos la violencia que se está registrando contra el personal médico con relación a la epidemia CoviD-19. Se identifican las principales fuentes de tensión estructural o amenazas que caracterizan el contexto actual, y se muestra la existencia de conductividad estructural entre ellas, dos características que pueden estar vinculadas a la violencia analizada. Se argumenta la importancia de políticas públicas para impedir que el problema crezca.

Palabras clave: agresiones a médicos, tensión estructural, conductividad estructural, políticas públicas

1 gresiones

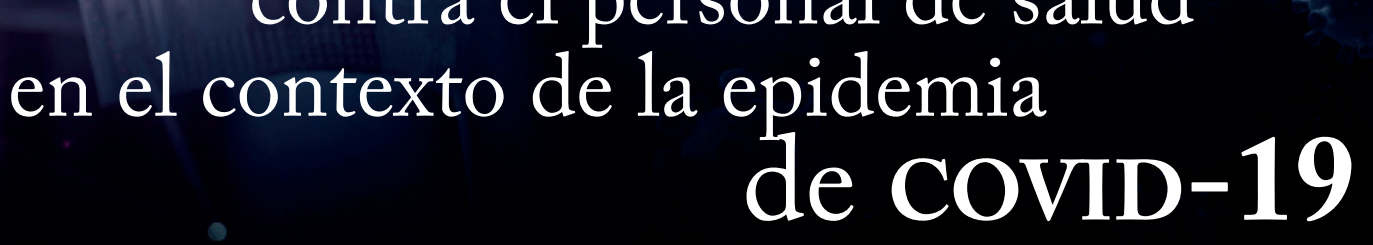

Apuntes hacia una reflexión sociológica

\section{El fenómeno}

Durante las últimas semanas ha surgido un nuevo fenómeno que se suma al complejo cuadro social que se desarrolla con relación a la epidemia de covid-19. Se trata de las agresiones hacia el personal de salud, cuya existencia han registrado los medios de comunicación masiva en varios lugares de México. ${ }^{1}$

Una rápida revisión de las diversas notas de prensa y mensajes en redes sociales sobre este tema nos permite advertir que tales agresiones se pueden clasificar en tres grupos:

Agresiones de desconocidos contra médicos y enfermeras fuera de las instituciones de salud. Ejemplos de este tipo son "invitaciones" que los vecinos de una unidad habitacional o edificio de depar-
Roberto Castro

rcastro@crim.unam.mx

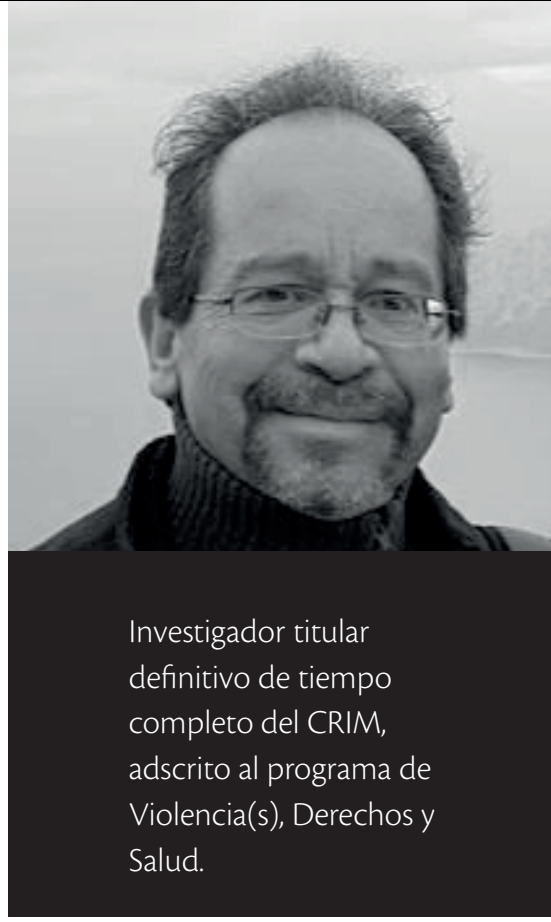


tamentos hacen a personal de salud que vive ahí para que se muden a otra parte, "para que no vayan a contagiar" a los demás vecinos; episodios donde algunos pasajeros de un transporte colectivo tipo "pesera", "ruta" o "combi" obligan a una enfermera a bajarse de la unidad, o bien agresiones físicas en donde una persona en la vía pública arroja cloro sobre una enfermera o incluso un vaso de café caliente, exigiéndole que se aleje porque la puede contaminar, entre otras (Barragán y Rodríguez, 2020; Pradilla y Vega, 2020).

Agresiones de pacientes o familiares de pacientes contra el personal, dentro de las instituciones de salud. Se han registrado varios altercados que incluyen discusiones airadas, jaloneos, empujones y agresiones físicas. Este tipo de incidentes responde al enojo de las personas porque el personal de salud no les trata como esperan, porque no se les permite estar junto con su familiar durante su agonía o porque no pueden despedirse de la persona enferma como se haría normalmente (Periódico Central, 2020).

Agresiones del personal de salud entre si dentro de las propias instituciones de salud. Este tipo de episodios consiste básicamente en actos de discriminación de parte del personal de salud contra aquellos médicos, médicas, enfermeras y enfermeros que están trabajando directamente en la atención a pacientes con covid $-19 .^{2}$

Cabe entonces preguntarnos ante qué estamos, de qué fenómeno más general son un dato estas agresiones y cómo pueden leerse en clave sociológica estos episodios para ganar una comprensión más profunda del problema. Esto último, "la lectura sociológica", es fundamental para poder acceder a una explicación que vaya más allá del mero sentido común o del sensacionalismo de la prensa, y nos permita formular intervenciones eficaces de política pública orientadas a detener cualquier tipo de agresiones al personal de salud.

\section{La tensión estructural}

En el estudio sociológico del comportamiento colectivo, Smelser (1996) propuso el concepto de tensión estructural para describir el conjunto de amenazas que constituyen una situación determinada. Orientados por ese concepto, podemos identificar varias fuentes de tensión que caracterizan la coyuntura actual en torno a la pandemia de covid-19. Desde el surgimiento de la epidemia se han reportado, a través de los medios de comunicación y las redes sociales, diversos problemas de infraestructura de los servicios de salud y carencia de materiales indispensables para la atención de los pacientes con este padecimiento (Dorantes, 2020).

En el primer caso estamos ante un insuficiente número de camas hospitalarias y respiradores para atender la demanda, en particular cuando la epidemia llegue al número máximo de personas infectadas que, de acuerdo con las proyecciones epidemiológicas oficiales (hasta la fecha), se espera para la segunda semana de mayo. Ello ha obligado a adoptar una estrategia de reconversión de algunos hospitales o de algunas secciones de estos, medida que a su vez ha generado episodios de resistencia y amenazas por parte de algunos segmentos de la sociedad (Pedroza, 2020). 
En el segundo caso estamos ante un insuficiente aprovisionamiento de mascarillas de seguridad, guantes, batas, goggles (gafas de seguridad) y demás materiales para el personal de salud, así como de la correcta capacitación para su manejo, aspectos indispensables para poder atender a los pacientes sin riesgo de infectarse. Ello ha dado lugar a diversos reclamos por parte del personal de salud hacia las autoridades, así como a la medida desesperada de comprarse ellos mismos sus propios insumos para poder trabajar, con la consecuente frustración y enojo que puede producir el hecho de tener que financiar al propio empleador o patrón para no correr riesgos.

A estas dos fuentes de tensión se añade una tercera, de más larga data, relacionada con la creciente falta de financiamiento suficiente a los servicios públicos de salud. Este factor, junto con lo que en otras investigaciones hemos llamado el habitus médico autoritario, se traduce en una experiencia negativa que un significativo número de usuarios tiene de estos servicios, bien porque deben esperar mucho tiempo para recibir un procedimiento terapéutico, bien porque perciben que son maltratados por el personal de salud durante la consulta o bien porque les genera frustración el hecho de que dichas instituciones carezcan con frecuencia de los medicamentos que ellas mismas les están recetando (Castro, 2014).

Por otra parte, ante el desarrollo de la epidemia, el pasado 30 de marzo el Consejo de Salubridad General decretó el estado de emergencia sanitaria para todo el país. Dicha medida implica la suspensión de todas las actividades económicas "no esenciales" y el llamado a la población en general al distanciamiento social y a permanecer en casa, medida que lleva vigente ya varias semanas y que se prevé deberá durar hasta fines del mes de mayo, para un total de nueve semanas (Secretaría de Salud, 2020).

La suspensión de actividades implica una fuente de honda preocupación para amplios sectores de la población que, tanto en la economía formal como en la informal, dependen de la venta diaria de sus productos y servicios para la supervivencia. Al enojo y la angustia provocada por no poder trabajar, se suma la tensión entre ciertos sectores que tienen las condiciones para permanecer en casa y algunos que no pueden hacerlo. Esto se expresa en las demandas de medidas de corte más bien autoritario que circulan sobre todo en las redes sociales, en el sentido de que las autoridades "deberían cerrar el metro de la Ciudad de México" o que "debería usarse a la Guardia Nacional" para obligar a las personas a permanecer en sus casas. Esta tensión real, percibida en el plano de las interacciones sociales cotidianas, tiene su correlato en el nivel estructural, observable en la disputa que existe entre las autoridades del sector salud - que tienen como prioridad controlar la epidemia - y los dirigentes del sector empresarial y productivo - que tienen como prioridad reanudar la actividad económica a la brevedad posible.

Por otra parte, el llamado a permanecer en casa ha dado lugar a un incremento de la violencia doméstica, tal como se ha documentado a través de diversas fuentes (Monroy, 2020). Es posible que dicha violencia se deba a varios factores, por ejemplo, la falta de espacios adecuados y suficientes para muchas familias, lo poco natural que resulta convivir bajo el mismo techo las veinticuatro horas del día, así como tener que compartir los recursos del hogar para poder seguir, en la medida de lo posible, con las actividades diarias (desde el 
uso del internet, en las casas donde lo hay, hasta espacios como la mesa del comedor o las habitaciones). La convivencia familiar obligada en condiciones de mayor o menor hacinamiento es un factor precipitante de la violencia de género e intrafamiliar.

\section{La conductividad estructural}

Todas las fuentes de tensión señaladas anteriormente se potencian entre sí y dan lugar a un creciente malestar social. De tal manera, en el caso del covid-19

\section{a}

Se trata de una epidemia totalizante que perturba

la relativa autonomía de los diversos campos sociales

y genera así un ambiente inédito cuya ruta de

navegación es desconocida para prácticamente la

totalidad de los agentes sociales."

estamos ante una epidemia que no se manifiesta únicamente en el campo de la salud, sino que involucra activamente los campos político, económico, comunicacional, el espacio de las relaciones familiares y de género e, incluso, el campo militar, pues ahora se ha dispuesto que la Guardia Nacional patrulle algunas de las principales instituciones de salud con el fin de evitar agresiones al personal que ahí trabaja (Gobierno de México, 2020).

Se trata de una epidemia totalizante que perturba la relativa autonomía de los diversos campos sociales y genera así un ambiente inédito, cuya ruta de navegación es desconocida para prácticamente la totalidad de los agentes sociales. Así, en el marco de la suma de tensiones antes descritas, la cuestión es dilucidar cómo estas se vinculan con las agresiones contra el personal de salud mencionadas al principio.

El clima de la pandemia formado, entre otras cosas, por la necesaria campaña de información impulsada desde la Secretaría de Salud, la indicación de quedarnos en nuestra casa, así como por la creciente socialización de los daños económicos que este periodo de cuarentena está significando para muchas personas ha generado un contexto de conductividad estructural, es decir, de una situación en la que diversos campos y espacios sociales están muy estrechamente vinculados.

Ambas, tensión y conductividad estructurales, son dos elementos cruciales pero no suficientes para el surgimiento de estallidos hostiles en situaciones de crisis. Esa combinación entre tensión y conductividad estructurales ha facilitado hasta ahora el surgimiento de pequeños y aislados episodios de agresiones a personal de salud, las cuales expresan el miedo de los agresores a ser contagiados, temor que se alimenta, desde luego, de falta de conocimiento sobre los mecanismos de transmisión del virus, de cierta desconfianza en que el personal de salud esté tomando todas las precauciones necesarias y de la experiencia social existente en torno a la precariedad de los servicios públicos de salud. En el contexto de las amenazas descritas, puede ocurrir que se activen rasgos autoritarios en algunos individuos, características que los llevan a agredir directamente al personal de salud con miras a imponer de manera rápida su propio punto de vista. 


\section{Conclusión}

En consecuencia, las agresiones al personal de salud en el contexto de la pandemia de covid-19 son un indicador de una estructura social tensionada de manera extrema en sus campos fundamentales y en sus niveles macro y micro. Además, se apoyan en la certeza de impunidad con que funcionan casi todos los transgresores en nuestra sociedad, la cual han aprendido por la vía de los hechos en el marco de tantos años de creciente criminalidad en este país, puesto que el Estado difícilmente tiene la capacidad para imputar responsabilidades a los individuos concretos.

En ese sentido, si bien el problema de las agresiones a médicos y enfermeras no ha adquirido grandes proporciones ni, al parecer, ha alcanzado modalidades graves o letales, es importante poner la mira en estas manifestaciones de intolerancia e intervenir sobre ellas. Es necesario detener las agresiones a médicos y sancionarlas, y no permitir que esos actos se conviertan en un nuevo elemento de una tensión estructural aún mayor. Por lo tanto, es indispensable una amplia campaña de promoción de la solidaridad para con el personal de salud.

a

Es necesario detener las agresiones a médicos

y sancionarlas, y no permitir que las mismas se

conviertan en un nuevo elemento de una tensión

estructural aún mayor. En ese sentido, una amplia

campaña de promoción de la solidaridad para con el

personal de salud es indispensable."

Más allá de las apreciaciones de sentido común (que encuentran indignantes o contraproducentes las agresiones al personal de salud), como científicos sociales siempre es útil preguntarnos, como lo hicimos al principio, ante qué estamos y de qué fenómeno más general es un dato lo que estamos viendo. Ello nos permite ponernos en modo sociológico y, así, hacer una especie de alejamiento de perspectiva (zoom out) que nos permita ver más allá del fenómeno que nos inquieta en sí, desentrañando sus vinculaciones con otros componentes de la estructura social y, eventualmente, incluso formular un diagnóstico acerca de las condiciones de posibilidad que permitirían un estallido más general de agresiones contra médicos y enfermeras. Por fortuna, parece que nos encontramos lejos de ello; de ahí la oportunidad de realizar la intervención de forma inmediata, para desmontar este escenario que ha comenzado a configurarse y a presentar indicios inquietantes.

\section{Notas}

1 Principalmente en los estados de Campeche, Chiapas, Chihuahua, Coahuila, Colima, Durango, Estado de México, Jalisco, Morelos, Nuevo León, Oaxaca, Puebla, San Luis Potosí, Sonora, Tabasco y Yucatán.

2 También se registró una discusión entre el personal médico y de enfermería y las autoridades de un hospital en Puebla. Los primeros reclamaban falta de insumos para poder trabajar en condiciones de seguridad y la disputa derivó en una riña a golpes entre algunos de los participantes. 


\section{Referencias bibliográficas}

Barragán, A. \& Rodríguez, D. (15 de abril de 2020). “Me gritaron 'traes el coviD’y me escupieron", las enfermeras en México sufren ataques por miedo al contagio. Verne. El Pais. Recuperado de https://verne.elpais.com/verne/2020/04/13/ mexico/1586810735_002679.html.

Castro, R. (2014).Génesis y práctica del habitus médico autoritario en México. Revista Mexicana de Sociología 76(2), 167-197.

Dorantes, E. (31 de marzo de 2020). Médicos del imss exigen insumos suficientes ante covid-19. El Sol de México. Recuperado de https:/www.elsoldemexico.com.mx/metropoli/cdmx/medicos-del-imss-hospitalgeneral-zona-27-exigen-insumos-suficientes-ante-COVID-19-5040325.html.

Monroy, J. (16 de abril de 2020). Segob: violencia intrafamiliar aumentó 120 \% desde la emergencia del covid-19. El $66 \%$ es por violencia física y $22 \%$ por violencia psicoemocional. El Economista. Recuperado de https://www.eleconomista.com.mx/politica/Segob-violencia-intrafamiliaraumento-120-desde-la-emergencia-del-COVID-19-20200416-0111.html.

Pedroza, E. (1. ${ }^{\circ}$ de abril de 2020). En Morelos, amagan con quemar hospital habilitado para atender pacientes con covid-19. Aristegui Noticias. Recuperado de https:// aristeguinoticias.com/0104/mexico/en-morelos-amagan-con-quemar-hospitalhabilitado-para-atender-pacientes-con-COVID-19/.

Periódico Central (14 de abril de 2020). Se agarran a golpes en el imss San José en medio de manifestación de médicos [Archivo de video]. Recuperado de https:// www.facebook.com/209099229232438/videos/2529385640618061/

Secretaría de Salud (2020). Acuerdo por el que se establecen acciones extraordinarias para atender la emergencia sanitaria generada por el virus SARS-CoV2. Publicado en Diario Oficial de la Federación el 31 de marzo de 2020.

Pradilla A. \& Vega, A. (21 de abril de 2020). "Se siente frustración, ¿̨por qué nos agreden?”: médicos son discriminados durante emergencia por COVID-19. Animal Politico. Recuperado de https://www.animalpolitico.com/2020/04/ medicos-agresiones-discriminacion-pandemia-COVID-19/.

Smelser, N. J. (1996). Teoría del comportamiento colectivo. México: Fondo de Cultura Económica.

Para citar esta nota: Castro, R. (23 de abril de 2020). Agresiones contra el personal de salud en el contexto de la epidemia de covid-19: apuntes hacia una reflexión sociológica. Notas de coyuntura del CRIM No. 1, México, CRIM-UnAm, 6pp. 